\title{
Dead space estimates may not be independently associated with 28-day mortality in COVID-19 ARDS
}

Luis Morales-Quinteros 1,2,3*0 (Ary Serpa Neto ${ }^{4,5,6,7}$, Antonio Artigas ${ }^{2,3,8,9}$, Lluis Blanch ${ }^{2,3,8,9}$, Michela Botta ${ }^{4}$, David A. Kaufman ${ }^{10}$, Marcus J. Schultz ${ }^{4,11,12}$, Anissa M. Tsonas ${ }^{4}$, Frederique Paulus ${ }^{4}$ and Lieuwe D. Bos ${ }^{4}$ on behalf of the PRoVENT-COVID Study Group

\begin{abstract}
Background: Estimates for dead space ventilation have been shown to be independently associated with an increased risk of mortality in the acute respiratory distress syndrome and small case series of COVID-19-related ARDS.

Methods: Secondary analysis from the PRoVENT-COVID study. The PRoVENT-COVID is a national, multicenter, retrospective observational study done at 22 intensive care units in the Netherlands. Consecutive patients aged at least 18 years were eligible for participation if they had received invasive ventilation for COVID-19 at a participating ICU during the first month of the national outbreak in the Netherlands. The aim was to quantify the dynamics and determine the prognostic value of surrogate markers of wasted ventilation in patients with COVID-19-related ARDS.

Results: A total of 927 consecutive patients admitted with COVID-19-related ARDS were included in this study. Estimations of wasted ventilation such as the estimated dead space fraction (by Harris-Benedict and direct method) and ventilatory ratio were significantly higher in non-survivors than survivors at baseline and during the following days of mechanical ventilation $(p<0.001)$. The end-tidal-to-arterial $\mathrm{PCO}_{2}$ ratio was lower in non-survivors than in survivors $(p<0.001)$. As ARDS severity increased, mortality increased with successive tertiles of dead space fraction by HarrisBenedict and by direct estimation, and with an increase in the VR. The same trend was observed with decreased levels in the tertiles for the end-tidal-to-arterial $\mathrm{PCO}_{2}$ ratio. After adjustment for a base risk model that included chronic comorbidities and ventilation- and oxygenation-parameters, none of the dead space estimates measured at the start of ventilation or the following days were significantly associated with 28-day mortality.
\end{abstract}

Conclusions: There is significant impairment of ventilation in the early course of COVID-19-related ARDS but quantification of this impairment does not add prognostic information when added to a baseline risk model.

Trial registration: ISRCTN04346342. Registered 15 April 2020. Retrospectively registered.

Keywords: Acute respiratory distress syndrome, ARDS, Respiratory dead space, Dead space, Ventilatory ratio, COVID19, Mortality, Prognostication

*Correspondence: luchomq2077@gmail.com

${ }^{1}$ Intensive Care Unit, Hospital Universitari General de Catalunya,

Grupo Quironsalud, Carrer Pedro i Pons, 1, 08195 Sant Cugat del Vallès, Barcelona, Spain

Full list of author information is available at the end of the article

\section{Background}

Since the outbreak of coronavirus disease 2019 (COVID19) in the City of Wuhan, Hubei Province, China, caused by the transmission of the novel coronavirus SARS$\mathrm{CoV}-2$, millions of individuals have been infected and more than one million have died. Severe disease requiring original author(s) and the source, provide a link to the Creative Commons licence, and indicate if changes were made. The images or other third party material in this article are included in the article's Creative Commons licence, unless indicated otherwise in a credit line to the material. If material is not included in the article's Creative Commons licence and your intended use is not permitted by statutory regulation or exceeds the permitted use, you will need to obtain permission directly from the copyright holder. To view a copy of this licence, visit http://creativecommons.org/licenses/by/4.0/. The Creative Commons Public Domain Dedication waiver (http://creativeco mmons.org/publicdomain/zero/1.0/) applies to the data made available in this article, unless otherwise stated in a credit line to the data. 
admission to intensive care unit (ICU) occurs in approximately $5 \%$ of infections [1], and the most common reason for admission is respiratory failure requiring high-level support. Among these patients, two-thirds meet the criteria for the acute respiratory distress syndrome (ARDS) [2].

Patients with COVID-19 pneumonia meeting criteria for ARDS usually present with a high respiratory drive and minute ventilation, potentially due to hypercapnia and an increased dead space fraction $\left(V_{\mathrm{D}} / V_{\mathrm{T}}\right)$ [3]. In patients with ARDS, an elevated $V_{\mathrm{D}} / V_{\mathrm{T}}$ is a predictor of death and is one of the few lung-specific physiological variables independently associated with mortality $[4,5]$. Methods for estimating $V_{\mathrm{D}} / V_{\mathrm{T}}$ do not require quantitative assessment of exhaled carbon dioxide, are less complicated to perform and easier to calculate at the bedside compared with calculations made by volumetric capnography [6]. In recent years, the ventilatory ratio (VR) was proposed as an easily acquired bedside index of impaired ventilation that can be computed using routinely measured respiratory variables [7]. In patients with ARDS, the VR correlates well with $V_{\mathrm{D}} / V_{\mathrm{T}}$ [7] and may function as a surrogate marker for impaired ventilation [8].

At least two independent groups have described series of patients with COVID-19-related ARDS who may have inefficient $\mathrm{CO}_{2}$ removal due to increased physiologic dead space $[3,9]$. However, few studies have assessed the impact for dead space ventilation mortality in a large cohort of COVID-19 patients undergoing invasive ventilation [10]. Therefore, we aimed to assess the association between markers of impaired ventilation, such as estimated $V_{\mathrm{D}} / V_{\mathrm{T}}$ and VR with 28-day mortality in patients undergoing invasive ventilation because of COVID-19 ARDS. We hypothesized that these markers of impaired ventilation are independently associated with 28-day mortality.

\section{Methods}

\section{Study design and oversight}

PRoVENT-COVID is an investigator-initiated, multicenter, observational cohort study undertaken at 22 ICUs in the Netherlands. The study protocol including the statistical analysis plan is available [11]. The approved protocol is available in Additional File 1. A statistical analysis plan for the current analysis was written before assessing the database and is available online [12]. Study sites were recruited through direct contact by members of the steering committee of PRoVENT-COVID. The institutional review boards of the participating centers approved the study protocol, and need for patient informed consent was waived. Study coordinators contacted the local doctors, trained data collectors to assist the local doctors and monitored the study according to the International Conference on Harmonization Good
Clinical Practice-guidelines. Integrity and timely completion of data collection was ensured by the study coordinators.

\section{Patients}

Consecutive patients $\geq 18$ years of age were eligible for participation in PRoVENT-COVID if they were admitted to one of the participating ICUs and had received invasive ventilation for COVID-19 ARDS. COVID19 infection was defined by a confirmed reverse transcriptase-polymerase chain reaction (RT-PCR) [13].

PRoVENT-COVID had no exclusion criteria, but for the current analysis, we excluded patients transferred from a non-participating hospital who had been receiving invasive ventilation for more than 2 calendar days, patients without complete data to calculate the $\mathrm{V}_{\mathrm{D}} / \mathrm{V}_{\mathrm{T}}$ or VR on the first day of ventilation, and patients with no data about 28-day mortality.

\section{Data collection}

Demographics and data regarding premorbid diseases and medication were collected at baseline. Ventilator settings and parameters were collected after one hour of invasive ventilation and every $8 \mathrm{~h}$ thereafter, for the first 4 calendar days. In the present study, the first day of ventilation is called 'at start of ventilation.'

\section{Data definition and exposure}

The primary exposure of interest was the $V_{D} / V_{T}$ calculated using the Harris-Benedict formula as described in Eq. (1) [14]:

$$
\frac{V_{\mathrm{D}}}{V_{\mathrm{T}}}=1-\frac{\left(0.863 * \dot{V} \mathrm{CO}_{2}\right)}{\left(\mathrm{RR} * V_{\mathrm{T}} * \mathrm{PaCO}_{2}\right)}
$$

$R R$ is the respiratory rate in breaths per minute, $V_{T}$ the tidal volume in liters, $\mathrm{PaCO}_{2}$ the partial pressure of carbon dioxide in $\mathrm{mmHg}$, and $\mathrm{VCO}_{2}$ the $\mathrm{CO}_{2}$ production in $\mathrm{mL} / \mathrm{min}$ estimated using Eq. (2):

$$
\dot{V} \mathrm{CO}_{2}=\frac{\mathrm{REE}_{\mathrm{HB}}}{\left(\frac{5.616}{\mathrm{RQ}}+1.584\right)}
$$

$\mathrm{RQ}$ is the respiratory quotient, assumed to be 0.8 , and $R E E_{H B}$ is the rest energy expenditure calculated by the unadjusted Harris-Benedict estimate using Eq. (3) [14]:

$$
\begin{aligned}
\text { Males : } \mathrm{REE}_{\mathrm{HB}}= & 66.473+(13.752 * \text { weight }) \\
& +(5.003 * \text { height })-(6.755 * \text { age }) \\
\text { Females : } \mathrm{REE}_{\mathrm{HB}}= & 655.096+(9.563 * \text { weight }) \\
& +(1.850 * \text { height })-(4.676 * \text { age })
\end{aligned}
$$


Weight is the actual body weight in kilograms, height is in centimeters and age in years.

In addition, two additional estimations of $\mathrm{V}_{\mathrm{D}} / \mathrm{V}_{\mathrm{T}}$ were done considering a direct estimation [6] and the endtidal-to-arterial $\mathrm{PCO}_{2}$ ratio [15], and the formulas are described in the Additional File 1.

The secondary exposure of interest is the VR, calculated using Eq. (4) [16]:

$$
\mathrm{VR}=\frac{\dot{V}_{E \text { measured }} * \mathrm{PaCO}_{2 \text { measured }}}{\dot{V}_{E \text { predicted }} * \mathrm{PaCO}_{2 \text { predicted }}}
$$

$\mathrm{VR}$ is the ventilatory ratio, $V_{\mathrm{E} \text { measured }}$ is the measured minute ventilation in $\mathrm{mL} / \mathrm{min}, \mathrm{PaCO}_{2}$ measured is the measured $\mathrm{PaCO}_{2}$ in $\mathrm{mmHg}, V_{\mathrm{E} \text { predicted }}$ is the predicted minute ventilation in $\mathrm{mL} / \mathrm{min}$ (calculated as 100 * predicted body weight) [16], and $\mathrm{PaCO}_{2}$ predicted is the predicted $\mathrm{PaCO}_{2}$ determined as $37.5 \mathrm{mmHg}$.

A post-hoc analysis was performed using Corrected Minute Ventilation as additional parameter of wasted ventilation. This parameter is calculated using the following formula:

$$
\dot{V}_{\mathrm{E} \text { corr }}=\frac{\dot{V}_{E} * \mathrm{PaCO}_{2}}{40 \mathrm{mmHg}}
$$

where $40 \mathrm{~mm} \mathrm{Hg}$ is the ideal value of $\mathrm{PaCO}_{2}$ [17]. This is reported in the Additional File 1. Additionally, the delta values between days were calculated and used as additional parameters and reported in the Additional File 1.

All variables were calculated three times per day, and the values were aggregated as the mean in the respective day. Primary analyses focused on the values obtained on the day on which ventilation was started.

\section{Outcomes}

The outcome assessed in this study was death at 28 days, defined as the mortality 28 days after the start of ventilation. Other clinical outcomes are reported only to describe the cohort but were not used to test their association with the exposures described above.

\section{Statistical analysis}

The amount of missing data was low for most of the variables (Table S1 in Additional File 1). Continuous variables are presented as median (quartile $25 \%$-quartile $75 \%$ ) and categorical variables as counts and percentages. Descriptive data are presented according to the 28-day status (non-survivors vs. survivors), and the two groups were compared using Wilcoxon rank-sum test for continuous variables, and Fisher exact tests for categorical variables.

Trends in markers of impaired ventilation were presented in boxplots between survivors and non-survivors over the first 4 calendar days. The direction of effect over time of the variables was assessed with mixed-effect linear models with center and patients treated as random effect to account for clustering and repeated measurements, and with 28-day vital status (alive/dead), time (as a continuous variable) and an interaction of 28-day vital status and time as fixed effect. Overall $P$ values from this analysis represent the overall difference among groups over time, and $P$ values from interaction represent a statistical assessment of whether the trend over time differed among the groups. All daily measurements of variables (three times a day) were aggregated as the mean per day. In addition, to compare variables at each day, the day variable was entered as a categorical variable in the model described above, and the $P$ value for the daily difference was extracted using pairwise comparisons after Bonferroni correction.

We examined the risk of death for each tertile of the lung-specific physiological variables used to evaluate whether the predictive ability of each variable varied by level. In addition, a simple stratification creating two groups according to the median of the variables was also assessed. The comparison of the two groups was presented in Kaplan-Meier curves and compared using Logrank tests.

Univariable mixed-effect generalized linear models considering a binomial distribution and with center as random effect were used to estimate the unadjusted effect of each variable on 28-day mortality. A multivariable mixed-effect generalized linear model considering a binomial distribution and with center as random effect were used to test the association of each of the exposures described above with 28-day mortality. A list of candidate confounders was determined a priori, and based on clinical relevance rather than statistical significance. The following baseline variables (measured at baseline or within $1 \mathrm{~h}$ after intubation or ICU admission with ventilation) were considered in the models: age, gender, body mass index, $\mathrm{PaO}_{2} / \mathrm{FiO}_{2}$ ratio, plasma creatinine, hypertension, diabetes, use of angiotensin converting enzyme inhibitors, use of angiotensin II receptor blockers, use of a vasopressor or an inotrope drug, fluid balance, $\mathrm{pH}$, mean arterial pressure, heart rate, respiratory system compliance and PEEP. Multicollinearity was assessed through the analysis of the variance inflation factors, and the final model was assessed for discrimination using c-statistics, and for calibration using the Brier-Score.

In addition to the odds ratio (OR) and its $95 \%$ confidence interval, the predictive accuracy of the lungspecific physiological variables was measured by the area under the receiver operating characteristics curve (AUC-ROC). Also, to estimate whether these variables improved predictive accuracy on top of that of the base model described above, the net reclassification 
improvement (NRI) and the integrated discrimination index (IDI) were assessed.

For the primary analysis, covariates with less than $3 \%$ of missing values were imputed by the median value of the overall cohort. Since respiratory compliance was missing in $8.2 \%$ of the patients (Table S1 in Additional File 1), an additional sensitivity analysis considering multiple imputation for all missing variables was conducted (described in details in Additional File 1).

All continuous variables were entered after standardization to improve convergence of the models, and the odds ratio (OR) represents the increase in one standard deviation of the variable. All analyses were conducted in R v.4.0.2 (R Foundation, Vienna, Austria) [18], and significance level was set at 0.05 .

\section{Results}

\section{Study population}

From March 1, 2020, through June 1, 2020, 31 ICUs were invited for participation in PRoVENT-COVID, and 22 of them met inclusion criteria. A total of 1340 individuals were screened. A total of 218 were not enrolled; 62 did not have COVID-19-related ARDS, 150 never received invasive ventilation, and 6 were excluded for other reasons (Additional File 1: Figure S1). Of the enrolled 927 patients, 259 (28.7\%) were non-survivors and 661 (71.3\%) were survivors at day 28. Demographics characteristics are presented in Table 1. Non-survivors were older, more often male, had a greater severity of ARDS and higher creatinine level at admission, more frequent presented co-existing disorders like hypertension, diabetes and chronic obstructive pulmonary disease, and more often were using systemic steroids, metformin, betablockers and statins at home. Ventilatory variables in the first day of ventilation and general clinical outcomes are shown in Table 2, Table S2 and Table S3 (Additional File 1). Non-survivors received higher $\mathrm{FiO}_{2}$, had higher levels of lactate and creatinine and lower levels of $\mathrm{pH}$ and endtidal-to-arterial $\mathrm{PCO}_{2}$. There were no differences in the radiographic findings between survivors and non-survivors (Table S15).

\section{Markers of impaired ventilation}

The dynamic change of markers of impaired ventilation over the first four days of ventilation as shown in Table 3 and Fig. 1. $V_{\mathrm{D}} / V_{\mathrm{T}}$ calculated using the Harris-Benedict formula was higher in non-survivors and increased more during the first four days compared to survivors. A similar trend was found with the direct $V_{\mathrm{D}} / V_{\mathrm{T}}$ calculation. While VR was also higher in non-survivors, especially after day 2, the end-tidal-to-arterial $\mathrm{PCO}_{2}$ ratio was lower.
Mortality by tertiles of each variable is reported in Fig. 2. Tertiles were calculated separately for each variable and each day, to account for potential differences in scaling and measurements. Mortality increased with successive tertiles of dead space fraction by Harris-Benedict and by direct estimation, and of ventilatory ratio, and decreased with successive tertiles of end-tidal-to-arterial $\mathrm{PCO}_{2}$ ratio.

Mortality over the first 28 days was higher in patients in the high group of dead space fraction by the HarrisBenedict estimation (16.4\% vs. $12.3 \%$; $p=0.003$ ), but not different in the groups considering the dead space fraction by direct estimation $(15.4 \%$ vs. $13.3 \% ; p=0.100)$, and the ventilatory ratio $(15.5 \%$ vs. $13.2 \% ; p=0.080$ ) (Fig. 3). When assessing the end-tidal-to-arterial $\mathrm{PCO}_{2}$ ratio, 28-day mortality was lower in the highest tertile group $(10.7 \%$ vs. $17.1 \%$; $p<0.001)$.

\section{Predictive accuracy of markers of impaired ventilation}

The unadjusted impact of each marker of impaired ventilation is shown in Additional File 1: Table S4. Estimated dead space fraction (by $\mathrm{HB}$ and direct method) and end-tidal-to-arterial $\mathrm{PCO}_{2}$ ratio were associated with 28-day mortality at the start of mechanical ventilation. Twenty-four hours after this, dead space fraction by Harris-Benedict and end-tidal-to-arterial $\mathrm{PCO}_{2}$ ratio were associated with 28-day mortality. The final multivariable base risk model is shown in Table S5 and in the Additional File 1. No problems were found due to multicollinearity or linearity assumption (Additional File 1: Tables S6 and S7).

After adjustment for the base risk model, none of the markers of impaired ventilation measured at the start of ventilation or the following day was significantly associated with 28-day mortality (Table 4). The inclusion of these variables did not improve the AUC-ROC compared to the base model (Fig. 4). The addition of dead space fraction by direct estimation at start of ventilation and of end-tidal-to-arterial $\mathrm{PCO}_{2}$ ratio at start of ventilation or day 1 slightly improved the predictive accuracy of the base model in terms of IDI (Table 4).

\section{Sensitivity analysis}

Results after multiple imputation were similar to the primary analysis (Additional File 1: Tables S8 and S9, and Figures S2 and S3).

\section{Post-hoc analysis}

All analyses described above were repeated for Corrected Minute Ventilation and yielded similar results (Additional File 1: Tables S9, S10, S11, S12, S13, S14 and Figures S4 and S5). The change in measures of wasted ventilation between day 3 and day 0 of intubation were 
Table 1 Baseline characteristics of the patients according to 28-day mortality

\begin{tabular}{|c|c|c|c|c|}
\hline & $\begin{array}{l}\text { All patients } \\
(n=927)\end{array}$ & $\begin{array}{l}\text { Non-survivors } \\
(n=266)\end{array}$ & $\begin{array}{l}\text { Survivors } \\
(n=661)\end{array}$ & $\begin{array}{l}p \\
\text { value }\end{array}$ \\
\hline Age, years & $65.0(57.0-72.0)$ & $70.0(64.0-75.0)$ & $63.0(55.0-70.0)$ & $<0.001$ \\
\hline Male gender-no (\%) & $668(72.1)$ & $206(77.4)$ & $462(69.9)$ & 0.023 \\
\hline Body mass index, kg/m² & $27.8(25.3-30.8)$ & $27.7(25.2-29.8)$ & $27.8(25.4-30.9)$ & 0.227 \\
\hline Severity of ARDS—no (\%) & & & & 0.020 \\
\hline Mild & 186/921 (20.2) & $45(17.0)$ & $141(21.5)$ & \\
\hline Moderate & $638 / 921(69.3)$ & $180(68.2)$ & $458(69.7)$ & \\
\hline Severe & $97 / 921(10.5)$ & $39(14.8)$ & $58(8.8)$ & \\
\hline \multicolumn{5}{|l|}{ Co-existing disorders—no (\%) } \\
\hline Hypertension & $317(34.2)$ & $112(42.1)$ & $205(31.0)$ & 0.002 \\
\hline Heart failure & $39(4.2)$ & $16(6.0)$ & $23(3.5)$ & 0.102 \\
\hline Diabetes & $207(22.3)$ & $78(29.3)$ & $129(19.5)$ & 0.002 \\
\hline Chronic kidney disease & $41(4.4)$ & $16(6.0)$ & $25(3.8)$ & 0.157 \\
\hline Baseline creatinine, $\mu \mathrm{mol} / \mathrm{L}^{*}$ & $76.0(62.0-97.0)$ & $84.0(65.0-112.0)$ & $74.0(61.0-92.0)$ & $<0.001$ \\
\hline Liver cirrhosis & $3(0.3)$ & $0(0.0)$ & $3(0.5)$ & 0.562 \\
\hline Chronic obstructive pulmonary disease & $76(8.2)$ & $32(12.0)$ & $44(6.7)$ & 0.011 \\
\hline Active hematological neoplasia & $15(1.6)$ & $6(2.3)$ & $9(1.4)$ & 0.388 \\
\hline Active solid neoplasia & $23(2.5)$ & $9(3.4)$ & $14(2.1)$ & 0.253 \\
\hline Neuromuscular disease & $8(0.9)$ & $3(1.1)$ & $5(0.8)$ & 0.696 \\
\hline Immunosuppression & $24(2.6)$ & $7(2.6)$ & $17(2.6)$ & 0.999 \\
\hline \multicolumn{5}{|l|}{ Previous medication-no (\%) } \\
\hline Systemic steroids & $35(3.8)$ & $17(6.4)$ & $18(2.7)$ & 0.012 \\
\hline Inhalation steroids & $108(11.7)$ & $40(15.0)$ & $68(10.3)$ & 0.054 \\
\hline Angiotensin converting enzyme inhibitor & $160(17.3)$ & $55(20.7)$ & $105(15.9)$ & 0.084 \\
\hline Angiotensin II receptor blocker & $101(10.9)$ & $35(13.2)$ & $66(10.0)$ & 0.164 \\
\hline \multicolumn{5}{|l|}{ Vital signs } \\
\hline Heart rate, bpm & $84.3(73.7-97.0)$ & $85.0(74.5-100.3)$ & $84.0(73.5-96.0)$ & 0.092 \\
\hline Mean arterial pressure, $\mathrm{mmHg}$ & $80.3(73.7-88.0)$ & $80.0(73.0-86.0)$ & $80.5(74.8-88.3)$ & 0.061 \\
\hline \multicolumn{5}{|l|}{ Organ support—no (\%) } \\
\hline Continuous sedation & $892(96.4)$ & $252(95.1)$ & $640(97.0)$ & 0.173 \\
\hline Inotropic or vasopressor & $733(79.2)$ & $216(81.5)$ & $517(78.3)$ & 0.324 \\
\hline Vasopressor & $732(79.1)$ & $216(81.5)$ & $516(78.2)$ & 0.283 \\
\hline Inotropic & $41(4.4)$ & $17(6.4)$ & $24(3.6)$ & 0.077 \\
\hline Fluid balance, $\mathrm{mL}$ & $631.5(50.0-1428.2)$ & $753.6(100.0-1482.0)$ & $593.0(34.0-1390.0)$ & 0.143 \\
\hline Urine output, mL & $702.5(370.0-1143.8)$ & $570.0(280.0-1075.0)$ & $725.0(415.0-1165.0)$ & 0.001 \\
\hline
\end{tabular}

Data are median (quartile $25 \%$-quartile $75 \%$ ) or No (\%). Percentages may not total 100 because of rounding

* Most recent measurement in $24 \mathrm{~h}$ before intubation, or at ICU admission under invasive ventilation

Table 2 Respiratory variables at start of ventilation

\begin{tabular}{|c|c|c|c|c|}
\hline & $\begin{array}{l}\text { All Patients } \\
(n=927)\end{array}$ & $\begin{array}{l}\text { Non-Survivors } \\
(n=266)\end{array}$ & $\begin{array}{l}\text { Survivors } \\
(n=661)\end{array}$ & $p$ value \\
\hline Tidal volume, mL/kg PBW & $6.4(5.9-7.1)$ & $6.5(5.9-7.2)$ & $6.4(5.9-7.1)$ & 0.175 \\
\hline $\operatorname{PEEP}\left(\mathrm{cmH}_{2} \mathrm{O}\right)$ & $12.7(11.0-14.5)$ & $13.0(11.2-15.0)$ & $12.7(10.7-14.3)$ & 0.091 \\
\hline Driving pressure $\left(\mathrm{cmH}_{2} \mathrm{O}\right)$ & $14.0(12.0-16.0)$ & $13.7(12.0-16.3)$ & $14.0(12.0-16.0)$ & 0.746 \\
\hline $\mathrm{PaO}_{2} / \mathrm{FiO}_{2}$ & 130.9 (99.9-175.5) & $137.2(98.1-180.0)$ & $128.8(100.2-171.5)$ & 0.262 \\
\hline $\mathrm{EtCO}_{2}$ & $36.5(32.6-41.6)$ & $34.7(31.7-40.2)$ & $37.0(33.2-42.0)$ & 0.001 \\
\hline Mechanical power (J/min) & $18.4(15.2-22.3)$ & $18.9(15.9-22.8)$ & $18.3(15.1-22.0)$ & 0.100 \\
\hline Compliance $\left(\mathrm{mL} / \mathrm{cmH}_{2} \mathrm{O}\right)$ & $33.2(26.7-40.3)$ & $33.8(26.7-40.7)$ & $32.9(26.7-40.1)$ & 0.899 \\
\hline
\end{tabular}

Data are median (quartile $25 \%$ - quartile $75 \%$ ). $\mathrm{FiO}_{2}$ : inspired fraction of oxygen; PEEP: positive end-expiratory pressure 
Table 3 Lung-specific physiological variables in the first four days of ventilation according to 28-day mortality

\begin{tabular}{|c|c|c|c|c|}
\hline & $\begin{array}{l}\text { All Patients } \\
(n=927)\end{array}$ & $\begin{array}{l}\text { Non-Survivors } \\
(n=266)\end{array}$ & $\begin{array}{l}\text { Survivors } \\
(n=661)\end{array}$ & $\begin{array}{l}p \\
\text { value* }\end{array}$ \\
\hline \multicolumn{5}{|l|}{ Dead space fraction by HB } \\
\hline At start of ventilation & $0.58 \pm 0.11$ & $0.60 \pm 0.11$ & $0.58 \pm 0.11$ & $<0.001$ \\
\hline Day 01 & $0.62 \pm 0.10$ & $0.64 \pm 0.09$ & $0.61 \pm 0.11$ & $<0.001$ \\
\hline Day 02 & $0.64 \pm 0.10$ & $0.67 \pm 0.09$ & $0.63 \pm 0.10$ & $<0.001$ \\
\hline Day 03 & $0.67 \pm 0.09$ & $0.69 \pm 0.08$ & $0.65 \pm 0.10$ & $<0.001$ \\
\hline$p$ value (interaction survival $\times$ day) & & 0.005 & & \\
\hline \multicolumn{5}{|l|}{ Dead space fraction direct } \\
\hline At start of ventilation & $2.22 \pm 0.55$ & $2.28 \pm 0.61$ & $2.19 \pm 0.52$ & 0.022 \\
\hline Day 01 & $2.35 \pm 0.54$ & $2.40 \pm 0.55$ & $2.33 \pm 0.54$ & 0.036 \\
\hline Day 02 & $2.48 \pm 0.58$ & $2.60 \pm 0.63$ & $2.44 \pm 0.54$ & $<0.001$ \\
\hline Day 03 & $2.62 \pm 0.65$ & $2.77 \pm 0.71$ & $2.56 \pm 0.61$ & $<0.001$ \\
\hline$p$ value (interaction survival $\times$ day) & & $<0.001$ & & \\
\hline \multicolumn{5}{|l|}{ Ventilatory ratio } \\
\hline At start of ventilation & $1.72 \pm 0.60$ & $1.77 \pm 0.56$ & $1.70 \pm 0.62$ & 0.114 \\
\hline Day 01 & $1.85 \pm 0.64$ & $1.88 \pm 0.53$ & $1.84 \pm 0.68$ & 0.142 \\
\hline Day 02 & $1.99 \pm 0.66$ & $2.09 \pm 0.60$ & $1.95 \pm 0.68$ & $<0.001$ \\
\hline Day 03 & $2.12 \pm 0.70$ & $2.26 \pm 0.68$ & $2.06 \pm 0.70$ & $<0.001$ \\
\hline$p$ value (interaction survival $\times$ day) & & $<0.001$ & & \\
\hline \multicolumn{5}{|l|}{ end-tidal-to-arterial $\mathrm{PCO}_{2}$ ratio } \\
\hline At start of ventilation & $0.85 \pm 0.18$ & $0.81 \pm 0.18$ & $0.87 \pm 0.18$ & $<0.001$ \\
\hline Day 01 & $0.84 \pm 0.14$ & $0.81 \pm 0.14$ & $0.85 \pm 0.13$ & $<0.001$ \\
\hline Day 02 & $0.82 \pm 0.14$ & $0.78 \pm 0.15$ & $0.83 \pm 0.14$ & $<0.001$ \\
\hline Day 03 & $0.80 \pm 0.15$ & $0.77 \pm 0.15$ & $0.81 \pm 0.14$ & $<0.001$ \\
\hline$p$ value (interaction survival $\times$ day) & & 0.455 & & \\
\hline
\end{tabular}

Data are median (quartile $25 \%$-quartile $75 \%$ )

HB: Harris-Benedict

*Calculated using pairwise contrasts in a mixed-effect generalized linear model considering a Gaussian distribution and with day, group and an interaction day $\times$ group as fixed effect, and with patients and center as random effect. A binomial distribution was used for binary variables and a Gaussian distribution for continuous

significantly associated with outcome (Additional File 1: Table S10). When restricting the analyses to patients with hypercapnia at presentation $\left(\mathrm{PaCO}_{2}>50 \mathrm{mmHg}\right)$ or prone positioning during the first day of mechanical ventilation, we did not observe large changes in effect sizes (Additional File 1: Table S12).

\section{Discussion}

The findings of this multicenter, observational cohort study of COVID-19-related ARDS patients showed that estimates for dead space ventilation increased over the first days of invasive ventilation and were significantly higher in non-survivors than survivors. However, none of these indices was independently associated with mortality when corrected for potential confounders. Therefore, wasted ventilation, and, tentatively, increased estimated dead space fraction, may be a marker for disease severity rather than an independent predictor of outcome.

Despite [19] the potential clinical value, $V_{\mathrm{D}} / V_{\mathrm{T}}$ is not routinely measured in daily critical care practice. One possible barrier is the requirement of volumetric capnography (or other techniques of analyzing exhaled gas) to measure $V_{\mathrm{d}} / V_{\mathrm{t}}$. Estimated measures for calculating $V_{\mathrm{D}} / V_{\mathrm{T}}$ are more frequently utilized and a wide array of these indices were included in this study $[6,20]$. VR is a recently validated index in patients under controlled modes of mechanical ventilation. This index was shown to be high in patients with COVID-19-related ARDS $[3,9]$ and is known to show moderate correlation with $V_{\mathrm{D}} / V_{\mathrm{T}}$ by volumetric capnography [7]. We found that the VR was not significantly different between survivors and non survivors at the start of ventilation and on day 1. However, we did find a significant difference in the following days of mechanical ventilation between survivors and non-survivors, not only for the VR but also for the rest of dead space estimates under study when a post-hoc analysis was performed (Table S14). This finding suggests the dynamic changes of these estimates over time are much more important than a single variable at the start 

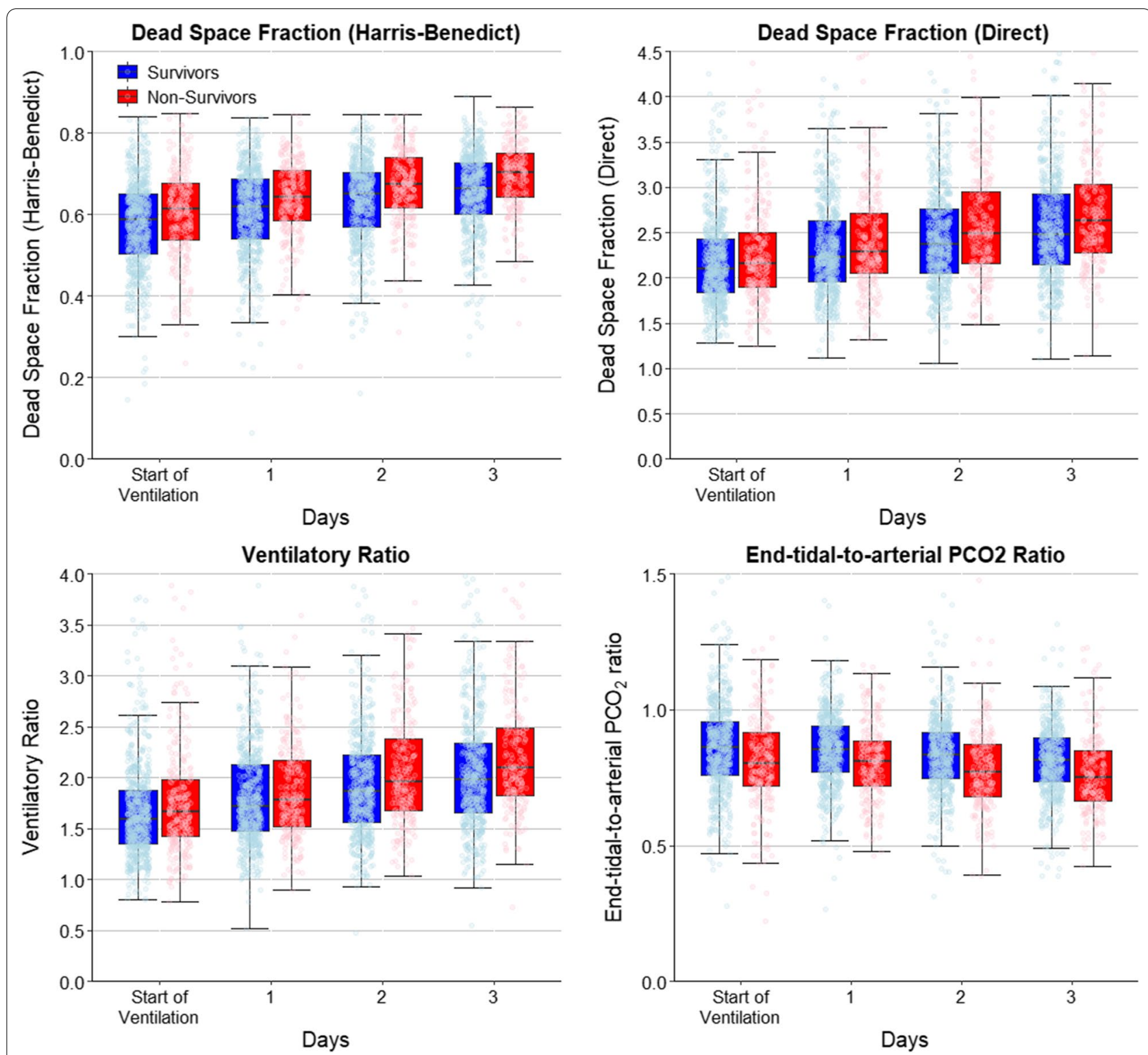

Fig. 1 Lung-specific physiological variables over the first four days of ventilation. Jitter boxplot of lung-specific physiological variables over the first four days of ventilation

of mechanical ventilation, also because this includes the response to optimization of ventilator settings.

Recently, the end-tidal-to-arterial $\mathrm{PCO}_{2}$ ratio $\left(\mathrm{P}_{\mathrm{ET}} \mathrm{CO}_{2} / \mathrm{PaCO}_{2}\right)$ has been described as another surrogate for $V_{\mathrm{D}} / V_{\mathrm{T}}$ in ARDS patients [15]. Each of these estimations has particular limitations, and they should be seen as complementary: if all point in the same direction, this likely reflects increased dead space ventilation. For example, in the presence of increased intrapulmonary shunt (as in ARDS patients), rising $\mathrm{PaCO}_{2}$ coincides with decreasing $\mathrm{P}_{\mathrm{ET}} \mathrm{CO} 2$. Both shunt and low cardiac output states are known determinants of $V_{\mathrm{D}} / V_{\mathrm{T}}$. It is worth noting that that the impact of cardiac output exists only when measuring $V_{\mathrm{D}} / V_{\mathrm{T}}$ the Enghoff modification of Bohr's original formula is used. In the case of shunt, the increase in venous admixture will elevate the $\mathrm{PaCO}_{2}$ increasing dead space fraction [21]. This contribution is of special importance when $V_{\mathrm{D}} / V_{\mathrm{T}}$ is high, where physiologic dead space can be contaminated by the large shunt fractions present in any type of ARDS. In low cardiac output states, a decrease in pulmonary blood flow leads to a reduced alveolar $\mathrm{CO}_{2}$ delivery decreasing $\mathrm{P}_{\mathrm{E}} \mathrm{CO}_{2}$, thereby increasing $V_{\mathrm{D}} / V_{\mathrm{T}}$ [22]. In both cases, indices for increase in dead space 


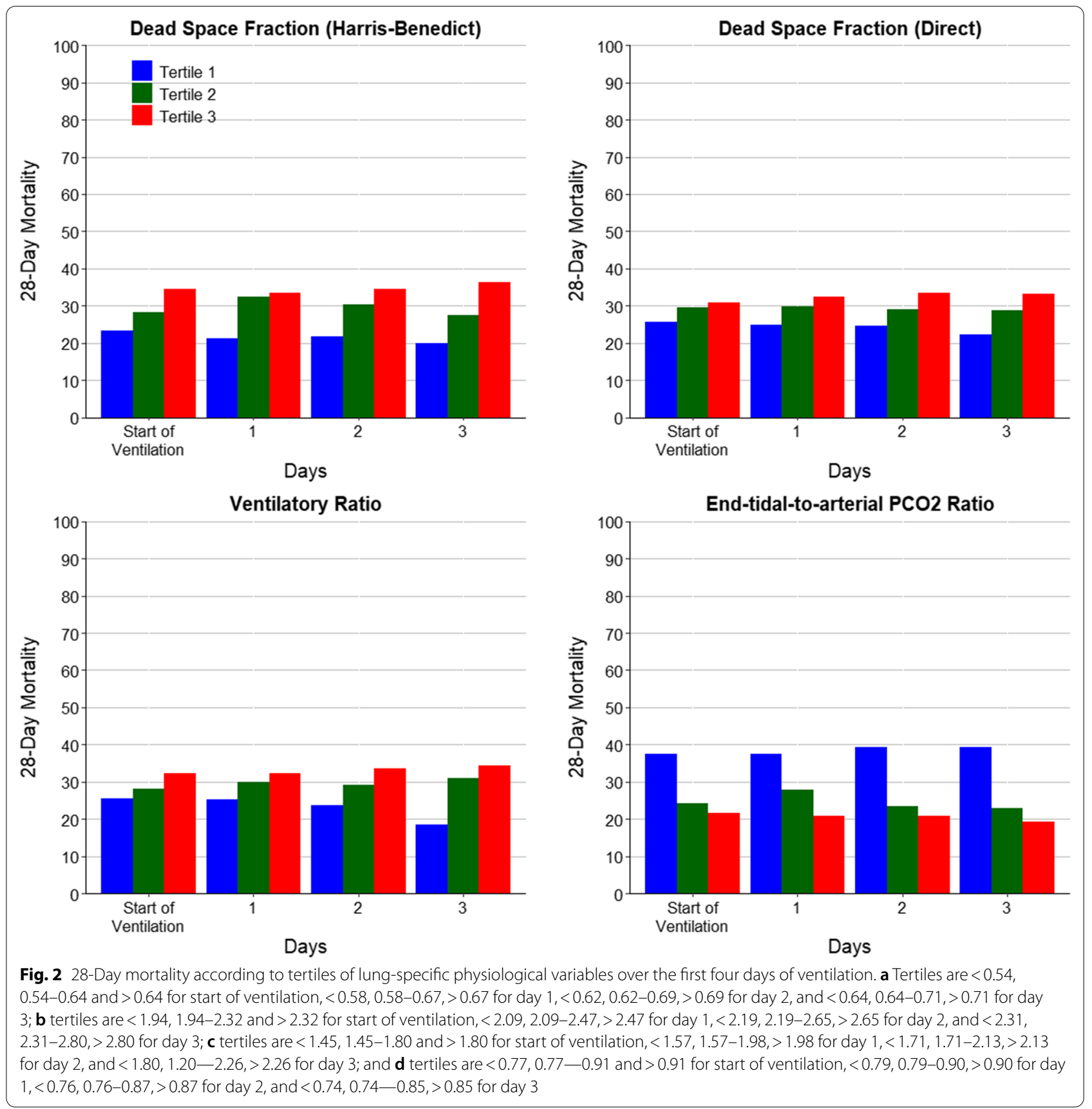

fraction would capture these phenomena and is hard to know each part's relative contribution in practice. Taken together, dead space indices reflect impaired outgassing of $\mathrm{CO}_{2}$ because of abnormal ventilation-perfusion matching giving a good global index of a lung's gas exchange efficiency [23, 24].

Dead space estimations were significantly increased in non-survivors in the first four days of mechanical ventilation compared to survivors. This is line with previous studies in all patients with ARDS (not only those with COVID19), in which dead space $\left(V_{\mathrm{D}} / V_{\mathrm{T}}\right)$ was elevated during the first week after start of invasive ventilation $[4,25]$. We also described the association between these indices and outcome that was previously observed in patients with ARDS due to other causes than COVID-19 $[4,25]$. However, in our study the investigated estimates did not add predictive value to a model that included other known predictors for 28-day mortality, with the 


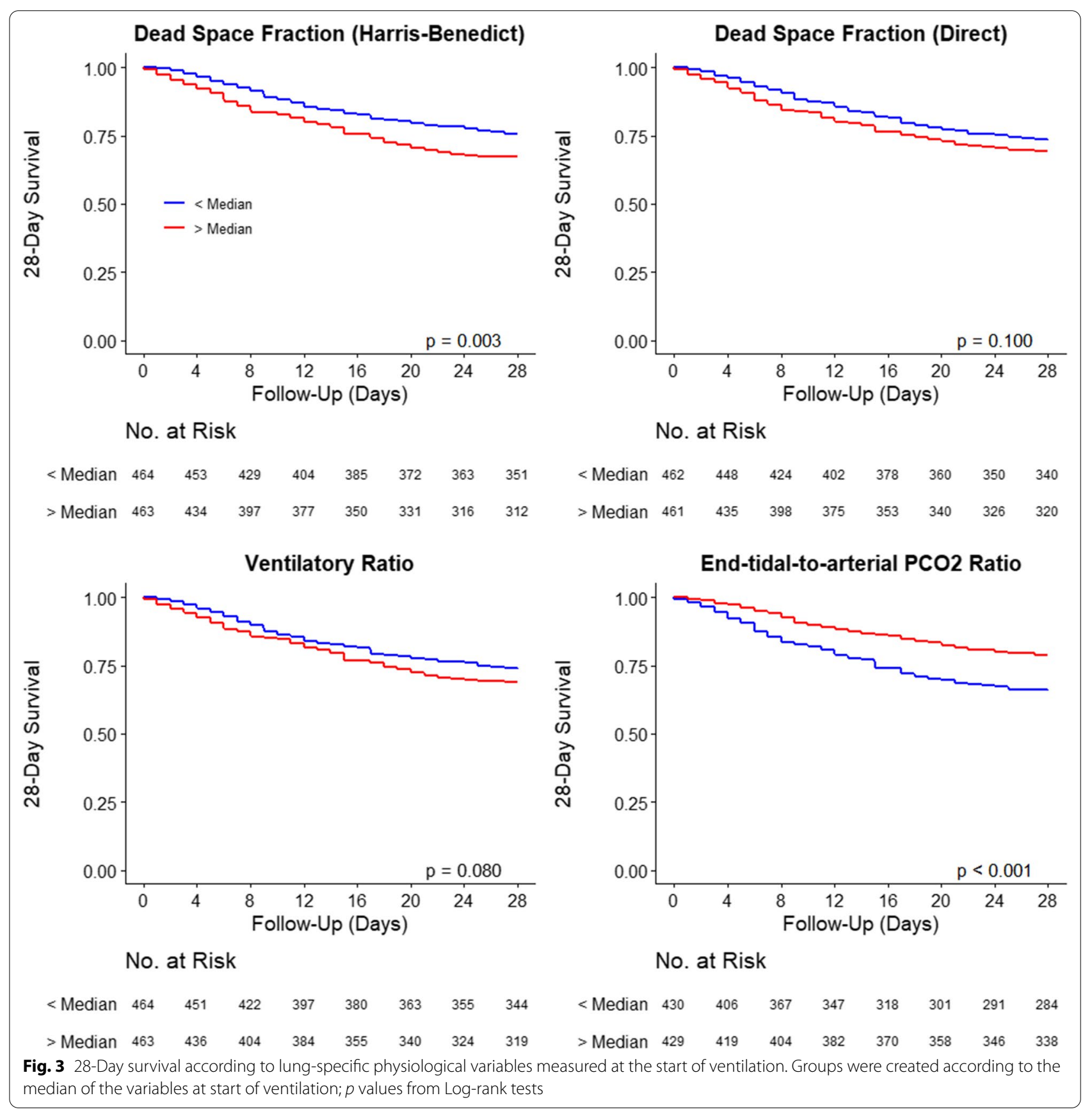

possible exception of $\mathrm{P}_{\mathrm{ET}} \mathrm{CO}_{2} / \mathrm{PaCO}_{2}$ at the start and at day 1 of ventilation. This contrasts with several studies in ARDS that showed increased dead space ventilation to be a robust and independent predictor of mortality risk [4, 25-27]. Decreasing $\mathrm{P}_{\mathrm{ET}} \mathrm{CO}_{2} / \mathrm{PaCO}_{2}$ was also independently associated with mortality risk in one study [15]. Yet, our findings are in line with a previous report in which we assessed the added value of markers of impaired ventilation during the first days of mechanical ventilation in non-COVID-19-related ARDS [8]. Taken together, the data suggest that markers of impaired ventilation reflect disease severity but are not independent predictors of outcome, irrespective of the cause of ARDS.

Although not the primary aim of this study, we observed that patients who were deceased were less frequently put in prone positioning (Table S2). Prone position facilitates shape matching, which helps minimizing injurious ventilation and frequently improves gas 
Morales-Quinteros et al. Crit Care

(2021) $25: 171$

Page 10 of 13

Table 4 Predictive accuracy of lung-specific physiological variables

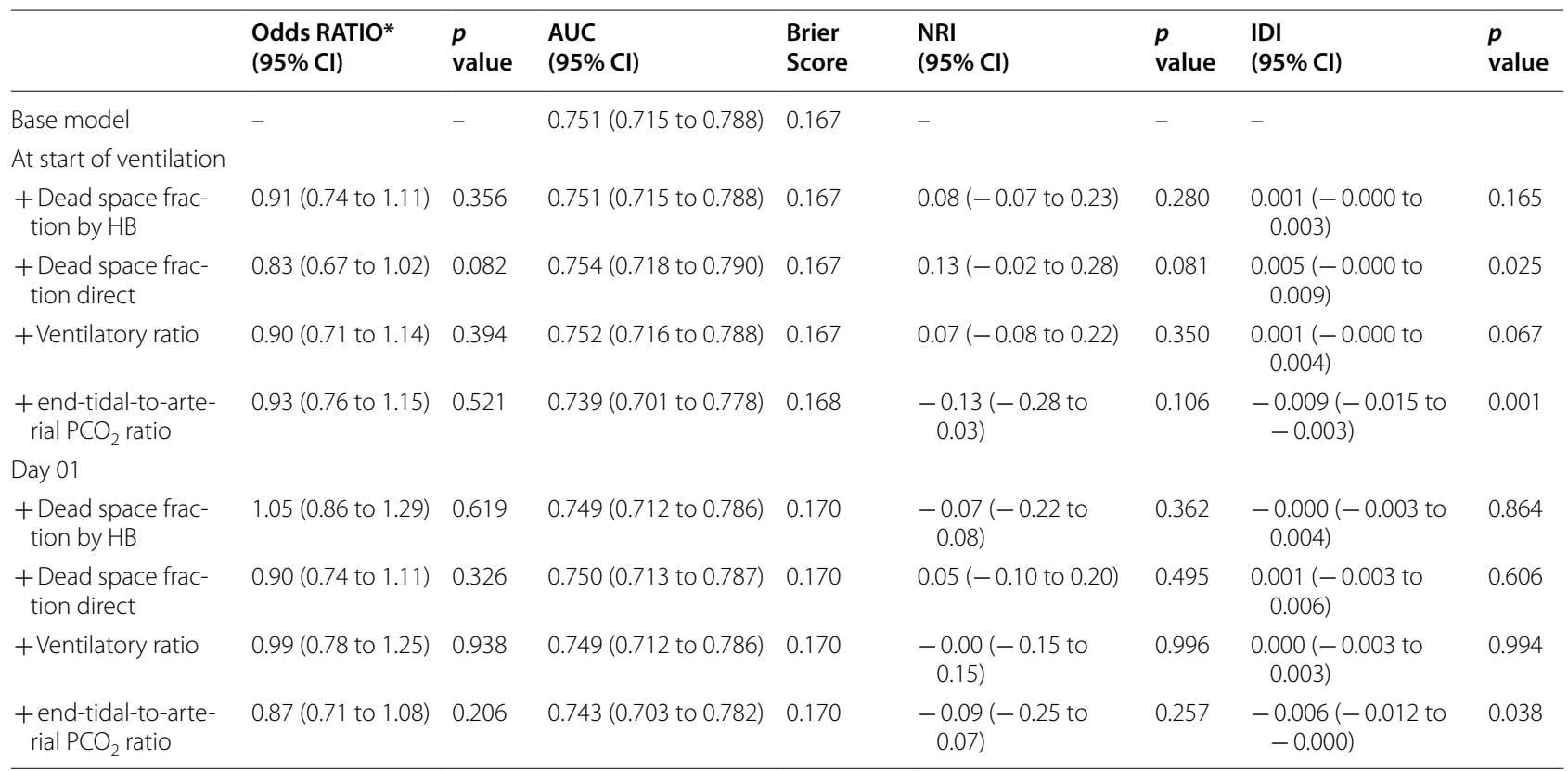

HB: Harris-Benedict; Cl: confidence interval; AUC: area under the curve; NRI: net reclassification index; IDI: integrated discrimination index

*Represents the odds ratio for the lung-specific physiological variables in the multivariable model

All models are mixed-effect models with centers as random effect and considering a binomial distribution

All continuous variables were entered after standardization to improve convergence of the model, and odds ratio represent the increase in one standard deviation of the variable

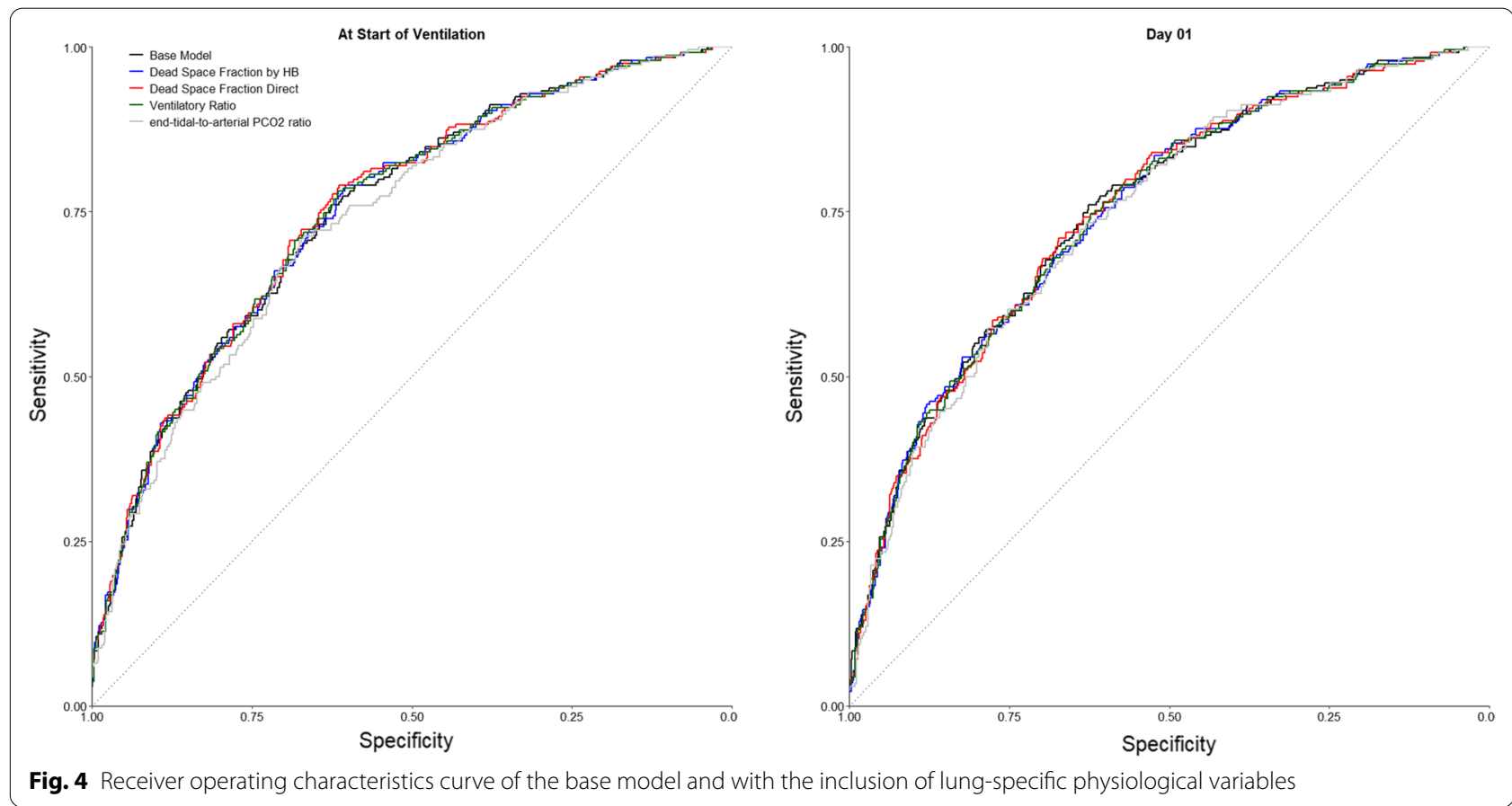


exchange through better $V / Q$ matching resulting in less shunt and improved $\mathrm{CO}_{2}$ clearance. Therefore, it could be postulated that prone positioning confounds the relation between surrogates of dead space ventilation and outcome. A post-hoc analysis, however, did not show a stronger association between these surrogates and outcomes in patients who did not receive prone position, yielding this explanation less likely.

In the current study in patients with COVID-19-related ARDS, impaired ventilation was already present in the first days of invasive ventilation. The studied estimations for $V_{\mathrm{D}} / V_{\mathrm{T}}$ further increased during the first days of invasive ventilation, especially in patients who did not survive. Altered hemostasis and thrombosis are postulated to be a key element of ARDS, with the endothelium playing a key role by promoting microthrombogenesis [2830]. Endothelial infection and activation and disorders of the microvasculature have been described in the pathogenesis of COVID-19 [19], and perfusion defects in the pulmonary arterial circulation are frequently observed [31]. Autopsy findings include pulmonary vascular microthrombi [32] in addition to diffuse alveolar damage. These findings could lead to high dead space fraction.

The strengths of this study include the size of the multi-center cohort, careful data collection and with few missing data, the pre-specified analysis plan, and the evaluation of multiple estimations for impaired ventilation. The central limitation of this study is that we did not quantify dead space ventilation directly by volumetric capnography or another technique. This was not possible in the setting of a pandemic, where the critical care systems were overwhelmed with patients. A second limitation is the observational nature of the study. Therefore, this study does not provide insight into potential mechanisms that may contribute to the association between high dead space estimations and mortality in COVID-19-related ARDS patients. Another important aspect to take into account is the aspect of the instrumental dead space. Use of heated humidifiers of HMEs (heat and moisture exchangers) is heterogeneous in the clinical practice, and different HMEs have different dead space volumes. Instrumental dead space may significantly affect the total dead space, mainly when using low tidal volume ventilation, and we have commented on this previously [33].

For the estimated $V_{\mathrm{D}} / V_{\mathrm{T}}$ computed by the Harris-Benedict formula, we assumed an RQ of 0.8 for $\mathrm{VCO}_{2}$ calculation based on a previous study [6]. Although the RQ may vary among ARDS patients, a recently previous work showed a good correlation between the VR (which also depends on the $\mathrm{VCO}_{2}$ ) and dead space measured with volumetric capnography [7].
The results of this study indicate that estimations for increased dead space may not be independently associated with mortality. The observed effect sizes were remarkably similar to those observed in non-COVID19-related ARDS. This contrasts several reports that have hypothesized that profound endothelial injury and coagulopathy may be central mediators of lung injury in COVID-19 [34]. We acknowledge that we did not measure these processes in this study, but we do provide evidence that COVID-19-related ARDS appears to be similar to non-COVID ARDS with respect to Vd/Vt. This implies that dead space and its estimates should be understood as a readily available marker of ARDS severity. Whether a high dead space identifies an enriched patient population with a higher prevalence of vascular injury, and who might benefit from treatments aimed at restoring normal pulmonary perfusion is unknown. Previous data suggest that some drugs with anticoagulant properties may decrease $V_{\mathrm{D}} / V_{\mathrm{T}}$ in patients with ARDS [35], making this an attractive hypothesis to consider.

At the moment, no data exists on the measurement of physiologic dead space in COVID-19-related ARDS by integrating volumetric capnography plots of eliminated $\mathrm{CO}_{2}$ concentration versus the respective expired tidal volume of a single breath. Since volumetric capnography offers a more in-depth representation of the kinetics of $\mathrm{CO}_{2}$ elimination per breath, the application of longitudinal or time-series models to analyze the effect of $\mathrm{CO}_{2}$ elimination impairment on outcome warrants further research.

\section{Conclusions}

Estimates for wasted ventilation are abnormal at the start of invasive ventilation in patients with COVID-19-related ARDS and worsen during consequent days. Ventilation impairment seems to be more extensive in non-survivors than in survivors, but they may not yield prognostic information when added to a baseline risk model. In the absence of bedside capnography, dead space estimates may serve as an important tool to assess the severity of COVID-19-related ARDS along with other variables such as oxygenation abnormalities and respiratory mechanics.

\footnotetext{
Abbreviations

ARDS: Acute respiratory distress syndrome; AUROCC: Area under the receiver operating characteristic curve; COVID-19: Coronavirus disease 2019; $\mathrm{FiO}_{2}$ Fraction of inspired oxygen; HB: Harris-Benedict; ICU: Intensive care unit; IBW: Ideal body weight; IDI: Integrated discrimination improvement; MERS: Middle East respiratory syndrome; $\mathrm{PaCO}_{2}$ : Partial pressure of carbon dioxide in arterial blood; $\mathrm{P}_{\mathrm{E}} \mathrm{CO}_{2}$ : Expired partial pressure of carbon dioxide; PEEP: Positive end expiratory pressure; $\mathrm{PaO}_{2}$ : Partial pressure of oxygen in arterial blood; $\mathrm{PaO}_{2} /$ $\mathrm{FiO}_{2}$ : Arterial oxygen tension to fraction of inspired oxygen; PRoVENT-COVID: PRactice of VENTilation in Patients with Coronavirus Disease 2019; SARS:
} 
Severe acute respiratory syndrome; $\mathrm{VCO}_{2}$ : Carbon dioxide consumption; $\mathrm{V}_{\text {Ecorr: }}$ Corrected minute ventilation; VR: Ventilatory ratio; $V_{D} N_{T}$ : Dead space fraction.

\section{Supplementary Information}

The online version contains supplementary material available at https://doi. org/10.1186/s13054-021-03570-0.

Additional file 1. Impaired ventilation is not associated with 28-day mortality in COVID-19 ARDS

\section{Acknowledgements}

\section{Not applicable.}

Author's information: A complete list of members of the PRoVENT-COVID collaborative group is provided:

STEERING COMMITTEE: (in alphabetic order) A.G. Algera, L.S. Boers; L.D.J. Bos; M. Botta; J. Pillay, D.A. Dongelmans, M.W. Hollmann; J. Horn; F. Paulus; A. Serpa Neto; M.J. Schultz; A.M. Tsonas, A.P. Vlaar.

STUDY COORDINATORS: (in alphabetic order) M. Botta; A.M. Tsonas. Investigators: (in alphabetic order): J.P. van Akkeren; A.G. Algera; C.K. Algoe; R.B. van Amstel; Artigas A; O.L. Baur; P. van de Berg; A.E. van den Berg; D.C.J.J. Bergmans; D.I. van den Bersselaar; F.A. Bertens; A.J.G.H. Bindels; M.M. de Boer; S. den Boer; L.S. Boers; M. Bogerd; L.D.J. Bos; M. Botta; J.S. Breel; H. de Bruin; S. de Bruin; C.L. Bruna; L.A. Buiteman-Kruizinga; O. Cremer; R.M. Determann; W. Dieperink; D.A. Dongelmans; H.S. Franke; M.S. Galek-Aldridge; M.J. de Graaff; L.A. Hagens; J.J. Haringman; S.T. van der Heide; P.L.J. van der Heiden; N.F.L. Heijnen; S.J.P. Hiel; L.L. Hoeijmakers; L. Hol; M. W. Hollmann; M.E. Hoogendoorn; J. Horn; R. van der Horst; E.L.K. le; D. Ivanov; N.P. Juffermans; E. Kho; E.S. de Klerk; A.W.M.M Koopman-van Gemert; M. Koopmans; S. Kucukcelebi; M.A. Kuiper; D.W. de Lange; N. van Mourik: Morales-Quinteros L; S.G. Nijbroek; M. Onrust; E.A.N. Oostdijk; F. Paulus; C.J. Pennartz; J. Pillay; L. Pisani; I.M. Purmer; T.C.D. Rettig; J.P Roozeman; M.T.U. Schuijt; M.J. Schultz; A. Serpa Neto; M.E. Sleeswijk; M.R. Smit; P.E. Spronk; W. Stilma; A.C. Strang; A. M. Tsonas; P.R Tuinman; C.M.A. Valk; F.L. Veen-Schra; L.I. Veldhuis; P. van Velzen; W.H. van der Ven A.P.J. Vlaar; P. van Vliet; P.H.J. van der Voort; L. van Welie; H.J.F.T. Wesselink; H.H. van der Wier-Lubbers; B. van Wijk; T. Winters; W.Y. Wong; A.R.H. van Zanten.

\section{Authors' contributions}

LMQ, LDB, AA, ASN, MJS and FP carried out the concept and design. LMQ, LDB and ASN carried out the statistical analysis. FP and MJS obtained funding for the present study. LDB and ASN carried out the supervision of the manuscript. $M B$, AT participated in the coordination of the study. All authors contributed in the acquisition, analysis, interpretation of data and drafting of the manuscript. All authors contributed to the critical revision of the manuscript for important intellectual content. All authors read and approved the final manuscript.

\section{Funding}

This article did not receive sponsorship for publication.

Declarations

\section{Availability of data and supporting materials}

Morales-Quinteros, Bos and Serpa Neto had full access to all data in the study and take responsibility for the integrity of the data and the accuracy of the data analysis; the members of the Steering Committee for PRoVENT-COVID Collaborative Group vouch for the accuracy and completeness of the data and for the fidelity of the study to the protocol.

\section{Declarations}

Ethics approval and consent to participate

Not applicable.

\section{Consent for publication}

Not applicable.

\section{Competing interests}

Dr Bos receives funding from the Dutch lung foundation (longfonds), from the Innovative Medicine Initiative and from Amsterdam UMC via the AUMC fellowship. The remaining authors have disclosed that they do not have any potential conflicts of interest.

\section{Author details}

${ }^{1}$ Intensive Care Unit, Hospital Universitari General de Catalunya, Grupo Quironsalud, Carrer Pedro i Pons, 1, 08195 Sant Cugat del Vallès, Barcelona, Spain. ${ }^{2}$ Universidad Autonoma de Barcelona, Barcelona, Spain. ${ }^{3}$ Institut D’Investigació, Innovació Parc Taulí I3PT, Sabadell, Spain. ${ }^{4}$ Department of Intensive Care \& Laboratory of Experimental Intensive Care and Anaesthesiology (L.E.I.C.A), Amsterdam UMC Location AMC, Amsterdam, The Netherlands. ${ }^{5}$ Department of Critical Care Medicine, Hospital Israelita Albert Einstein, São Paulo, Brazil. ${ }^{6}$ Australian and New Zealand Intensive Care Research Centre (ANZIC-RC), Monash University, Melbourne, Australia. ${ }^{7}$ Data Analytics Research and Evaluation (DARE) Centre, Austin Hospital and University of Melbourne, Melbourne, Australia. ${ }^{8}$ Critical Care Center, Corporacion Sanitaria Universitaria Parc Taulí, Sabadell, Spain. ${ }^{9}$ CIBER Enfermedades Respiratorias (ISCiii), Madrid, Spain. ${ }^{10}$ Division of Pulmonary, Critical Care, and Sleep Medicine, NYU School of Medicine, New York, NY, USA. ${ }^{11}$ Nuffield Department of Medicine, Oxford University, Oxford, UK. ${ }^{12}$ Mahidol-Oxford Tropical Medicine Research Unit (MORU), Mahidol University, Bangkok, Thailand.

Received: 21 January 2021 Accepted: 8 April 2021

Published online: 17 May 2021

\section{References}

1. Wu Z, McGoonan JM. Characteristics of and important lessons from the Coronavirus Disease 2019 (COVID-19) outbreak in China: summary of a report of 72,314 cases from the Chinese Center for Disease Control and Prevention. JAMA. 2020;323:1239-42.

2. Wang D, Hu B, Hu C, et al. Clinical characteristics of 138 hospitalized patients with 2019 novel coronavirus-infected pneumonia inWuhan, China. JAMA. 2020;323:1061-9.

3. Liu X, Liu X, Xu Y, et al. Ventilatory ratio in hypercapnic mechanically ventilated patients with COVID-19 associated ARDS. Am J Respir Crit Care Med. 2020;201:1297-9.

4. Nuckton TJ, Alonso JA, Kallet RH, et al. Pulmonary dead-space fraction as a risk factor for death in the acute respiratory distress syndrome. N Engl J Med. 2002:346:1281-6.

5. Kallet RH, Zhuo H, Liu KD, et al. The association between physiologic dead-space fraction and mortality in subjects with ARDS enrolled in a prospective multi-center clinical trial. Respir Care. 2014;59:1611-8.

6. Beitler JR, Thompson BT, Matthay MA, et al. Estimating dead-space fraction for secondary analyses of acute respiratory distress syndrome clinical trials. Crit Care Med. 2015:43:1026-35.

7. Sinha P, Calfee CS, Beitler JR, et al. Physiologic analysis and clinical performance of the ventilatory ratio in acute respiratory distress syndrome. Am J Respir Crit Care Med. 2019;199:333-41.

8. Morales-Quinteros L, Schultz MJ, Bringué J, et al. Estimated dead space fraction and the ventilatory ratio are associated with mortality in early ARDS. Ann Intensive Care. 2019;9:128.

9. Schenck EJ, Hoffman K, Goyal P, et al. Respiratory mechanics and gas exchange in COVID-19 Associated Respiratory Failure. Ann Am Thorac Soc. 2020;17:1158-61.

10. Fusina F, Albani F, Bertelli M, et al. Corrected Minute Ventilation Is Associated With Mortality in ARDS Caused by COVID-19. Respir Care. 2020;66:619.

11. Boers NS, Botta M, Tsonas AM, et al. Practice of Ventilation in Patients with Novel Coronavirus Disease (PRoVENT-COVID): rationale and protocol for a national multicenter observational study in The Netherlands. Ann Transl Med. 2020;2020(8):1251.

12. Paulus F. https://sites.google.com/view/provent-covid/provent-covid? authuser $=0$. Accessed 12 Jan 2021

13. Prokop M, van Everdingen W, et al. CO-RADS - A categorical CT assessment scheme for patients with suspected COVID-19: definition and evaluation. Radiology. 2020;296:E97-104.

14. Harris JA, Benedict FG. A biometric study of human basal metabolism. Proc Natl Acad Sci USA. 1918;4:370-3. 
15. Kallet RH, Lipnick MS. End-tidal-to-arterial pco2 ratio as signifier for physiologic deadspace ratio and oxygenation dysfunction in acute respiratory distress syndrome. Respir Care. 2021;66:263-8.

16. Sinha P, Fauvel NJ, Singh S, et al. Ventilatory ratio: a simple bedside measure of ventilation. Br J Anaesth. 2009;102:692-7.

17. Wexler HR, Lok P. A simple formula for adjusting arterial carbon dioxide tension. Can Anaesth Soc J. 1981;28:370-2.

18. R Core Team (2019). R: A language and environment for statistical computing. R Foundation for Statistical Computing, Vienna, Austria. https:// www.R-project.org/.

19. Varga Z, Flammer AJ, Steiger $P$, et al. Endothelial cell infection and endotheliitis in COVID-19. Lancet. 2020;395:1417-8.

20. Siddiki H, Kojicic M, Li G, et al. Bedside quantification of dead-space fraction using routine clinical data in patients with acute lung injury: secondary analysis of two prospective trials. Crit Care. 2010;14:R141.

21. Sinha P, Flower O, Soni N. Deadspace ventilation: a waste of breath! Intensive Care Med. 2011;37:735-46.

22. Mosing M, Kutter AP, Iff $S$, et al. The effects of cardiac output and pulmonary arterial hypertension on volumetric capnography derived-variables during normoxia and hypoxia. J Clin Monit Comput. 2015;29:187-96.

23. Suarez-Sipmann F, Bohm S, Tusman G. Volumetric capnography: the time has come. Curr Opin Crit Care. 2014;20:333-9.

24. Lucangelo $U$, Bernabè $F$, Vatua $S$, et al. Prognostic value of different dead space indices in mechanically ventilated patients with acute lung injury and ARDS. Chest. 2008;133:62-71.

25. Kallet RH, Alonso JA, Pittet JF, et al. Prognostic value of the pulmonary dead-space fraction during the first 6 days of acute respiratory distress syndrome. Respir Care. 2004;49:1008-14.

26. Kallet $\mathrm{RH}$, Zhuo H, Ho K, et al. Lung injury Etiology and other factors influencing the relationship between dead-space fraction and mortality in ARDS. Respir Care. 2017:62:1241-8.
27. Raurich JM, Vilar M, Colomar A, et al. Prognostic value of the pulmonary dead-space fraction during the early and intermediate phases of acute respiratory distress syndrome. Respir Care. 2010;55:282-7.

28. Chang JC. Hemostasis based on a novel "two-path unifying theory" and classification of hemostatic disorders. Blood Coagul Fibrinol. 2018;29:573-84.

29. Chang JC. Thrombogenesis and thrombotic disorders based on "twopath unifying theory of hemostasis": philosophical, physiological and phenotypical interpretation. Blood Coagul Fibrinol. 2018;29:585-95.

30. Chang JC. Acute respiratory distress syndrome as an organ phenotype of vascular microthrombotic disease: based on hemostatic theory and endothelial molecular pathogenesis. Clin Appl Thromb. 2019;25:1-20.

31. Beenen LFM, Bos LB, Scheerder MJ, et al. Extensive pulmonary perfusion defects compatible with microthrombosis and thromboembolic disease in severe Covid-19 pneumonia. Thromb Res. 2020;135-137:135-7.

32. Wichmann $D$, Sperhake JP, Lütgehetmann M, et al. Autopsy findings and venous thromboembolism in patients with COVID-19: a prospective cohort study. Ann Intern Med. 2020;173:268-77.

33. Schultz MJ, Bos LDJ, Paulus F. Instrumental dead space in ventilator management - authors'reply. Lancet Respir Med. 2021;9:e23.

34. Patel BV, Arachchillage DJ, Ridge CA, et al. Pulmonary angiopathy in severe COVID-19: physiologic, imaging, and hematologic observations. Am J Respir Crit Care Med. 2020;202:690-9.

35. Liu KD, Levitt J, Zhuo H, et al. Randomized clinical trial of activated protein $\mathrm{C}$ for the treatment of acute lung injury. Am J Respir Crit Care Med. 2008; 178:618-23.

\section{Publisher's note}

Springer Nature remains neutral with regard to jurisdictional claims in published maps and institutional affiliations.
Ready to submit your research? Choose BMC and benefit from:

- fast, convenient online submission

- thorough peer review by experienced researchers in your field

- rapid publication on acceptance

- support for research data, including large and complex data types

- gold Open Access which fosters wider collaboration and increased citations

- maximum visibility for your research: over $100 \mathrm{M}$ website views per year

At BMC, research is always in progress.

Learn more biomedcentral.com/submissions 